British Journal of Medicine \& Medical Research
17(7): 1-7, 2016, Article no.BJMMR.28382
ISSN: 2231-0614, NLM ID: 101570965
SCIENCEDOMAIN international
wWw.sciencedomain.org

\title{
Invest to Progress? A Survey of the Cost of Postgraduate Training Prior to Specialty Applications in the United Kingdom
}

\author{
Nicholas Bullock ${ }^{1,2,3}$, Stephanie Wallis ${ }^{1,2}$ and Ronak Ved ${ }^{3^{\star}}$ \\ ${ }^{1}$ University of Bristol, UK. \\ ${ }^{2}$ University Hospitals Bristol NHS Foundation Trust, UK. \\ ${ }^{3}$ Cardiff and Vale University Health Board, UK.
}

\begin{abstract}
Authors' contributions
This work was carried out in collaboration between all authors. Author NB designed the study and wrote the first draft of the manuscript. Authors NB, SW and RV managed the literature searches, analysis of the study data, and development of the manuscript. All authors read and approved the final manuscript.
\end{abstract}

\section{Article Information}

DOI: 10.9734/BJMMR/2016/28382

Editor(s):

(1) Thomas I. Nathaniel, University of South Carolina, School of Medicine-Greenville, Greenville, SC 29605, USA.

Reviewers:

(1) Emma Stodel, University of Ottawa, Ontario, Canada.

(2) Utku Kose, Usak University, Turkey.

(3) Z. O. Amarin, Jordan University of Science and Technology, Jordan. Complete Peer review History: http://www.sciencedomain.org/review-history/15942

Short Communication

Received $16^{\text {th }}$ July 2016

Accepted $18^{\text {th }}$ August 2016

Published 26 ${ }^{\text {th }}$ August 2016

\section{ABSTRACT}

Aim: Clinical training is expensive. This survey of foundation doctors across four UK foundation deaneries (Severn, Wales, South Thames and Scotland) identifies that highly variable sums of money were spent by foundation doctors applying for specialty training.

Place and Duration of Study: Bristol Royal Infirmary and University Hospital of Wales, between September 2015 and July 2016.

Methodology: A total of 1506 foundation year two (FY2) doctors were invited to participate in the online survey. Participants were canvassed via ten questions pertaining to their involvement in four groups of career enhancing activities: training courses; postgraduate examinations; qualifications, and conference attendances. The survey was closed after a 'live' period of 5 months. 100 FY2 doctors had completed the survey at the time of its closure. 
Results: Of the 100 participants, $89(89.0 \%)$ had undertaken at least one career enhancing activity, with a mean expenditure of $£ 1460$ per respondent. Surgical and academic programme applicants spent on average over double the amount of those for anaesthetics $(p=0.01)$ and medicine $(p=0.001)$ and ten times that of applicants to general practice $(p=0.0001)$.

Conclusions: These results have potential implications for training expectations, allocation of study budgets and specialty application processes as a whole.

Keywords: Cost specialty training medical education.

\section{INTRODUCTION}

Postgraduate medical training in the United Kingdom (UK) is expensive, with doctors spending an average of $£ 17 \quad 114$ prior to obtaining their Certificate of Completion of Training [1]. Alongside inevitable expenses such as those associated with indemnity insurance and transport, a significant proportion of trainees' educational expenses may include spending personal funds on career enhancing activities, such as completion of training courses, postgraduate exams and attendance at conferences. These expenses have been estimated to cost junior doctors up to $£ 7000$ [2]. Whilst these estimated figures have been assumed to vary based on trainee specialty, this has only rarely been assessed in peer reviewed literature [1,2]. Furthermore, there is little published work assessing precisely when during their training junior doctors are spending money on these career-enhancing activities. Identifying these variables in spending would provide useful information to optimize training curricula, study budgets allocations, and the pricing of careerenhancing activities.

Training bodies do stipulate that many of these activities should be completed by the end of early specialist training. For example, successful completion of the Membership of the Royal College of Surgeons (MRCS) and Membership of the Royal College of Physicians (MRCP) examinations are formal exit requirements for Core Surgical and Core Medical Training $[3,4]$. Career enhancing activities have been demonstrated to enhance the knowledge and experience of the individual trainee. For example, the Advanced Trauma Life Support course (ATLS) has been shown to improve the knowledge and skills of participants in the management of multiple trauma patients [5]. Furthermore, the completion of a qualification or course in medical education has been shown to improve doctors teaching skills $[6,7]$. However, with high levels of competition and the allocation of points for these activities during recruitment, are juniors completing career enhancing activities earlier on in their training in order to gain a competitive advantage over their peers? If so, there is a need to identify how much money new junior doctors are spending on these activities.

This study sought to establish the range and associated costs of career enhancing activities being undertaken by Foundation Doctors in the UK prior to specialty training application.

\section{METHODOLOGY}

Foundation Year Two (FY2) doctors working within four Foundation Schools (Scotland, Severn, South Thames and Wales) who had applied for specialty training commencing August 2015 were invited to participate in the study. An online questionnaire was distributed to participants, comprising ten questions pertaining to their involvement in four groups of career enhancing activities: training courses, postgraduate examinations, qualifications, and conference attendances. Invitations were disseminated via email and social media between January and March 2015. Altogether, 1506 foundation doctors were invited to participate in the survey (Wales 318; Severn 280; South Thames 834; Scotland 74). Responses were limited to one per I.P. address to minimise the risk of duplication. The survey was closed once 100 responses were received, after which data analysis was undertaken.

Primary outcome was the total amount spent on career enhancing activities prior to specialty training applications. Mean total expenditures for each specialty were compared to that of academic and surgical applicants using the independent student's t-test. A p-value of $<0.05$ was considered statistically significant.

\section{RESULTS}

Response rates were distributed across deaneries as follows: Scotland 10/74 (13.0\%); Severn 45/280 (16.1\%); South Thames 32/834 
(3.8\%); Wales $13 / 318$ (4.1\%). The demographics of respondents are outlined in Table 1.

Table 1. Respondent demographics

\begin{tabular}{ll}
\hline & $\mathbf{n}(\%)$ \\
\hline Age group & \\
$21-25$ & $35(35.0)$ \\
$26-30$ & $56(56.0)$ \\
$31-35$ & $8(8.0)$ \\
$>35$ & $1(1.0)$ \\
Nature of medical qualification & \\
$\quad$ Undergraduate & $78(78.0)$ \\
$\quad$ Postgraduate & $19(19.0)$ \\
$\quad$ Not disclosed & $3(3.0)$ \\
Foundation school & \\
Scotland & $10(10.0)$ \\
Severn & $45(45.0)$ \\
South Thames & $32(32.0)$ \\
Wales & $13(13.0)$ \\
\hline
\end{tabular}

Of the 100 respondents, a total of $89(89.0 \%)$ reported undertaking at least one form of career enhancing activity, with attendance at conferences $(n=59 ; 59.0 \%)$ and the completion of training courses $(n=56 ; 56.0 \%)$ being the two most popular. The most frequently reported motivation was a desire to increase competitiveness for specialty applications $(\mathrm{n}=71 ; 71.0 \%)$, followed by a desire to develop knowledge and skills $(n=66 ; 66.0 \%)$.

The number of participants and the amount spent on each activity, as totals, and stratified by intended specialty, are given in Table 1 and Fig. 1.

The mean total amount spent by each participant was $£ 1460$, with those applying for academic training and surgical specialties investing the most (mean totals of £3572 and £2535 respectively). Those applying for Surgery and academic specialities spent significantly greater total amounts than their colleagues that applied for: anaesthetics \& emergency medicine $(p=$ $0.01)$; medicine $(p=0.001)$; paediatrics $(p=$ $0.008)$ and general practice $(p=0.0001)$. A comparison of mean spending per group is illustrated in Fig. 2.

Surgical and academic scheme applicants had the greatest outlays for every career enhancing activity when compared to spending of applicants to other specialities. Comparison of spending on activities between specialty application groups is further illustrated in Fig. 3.

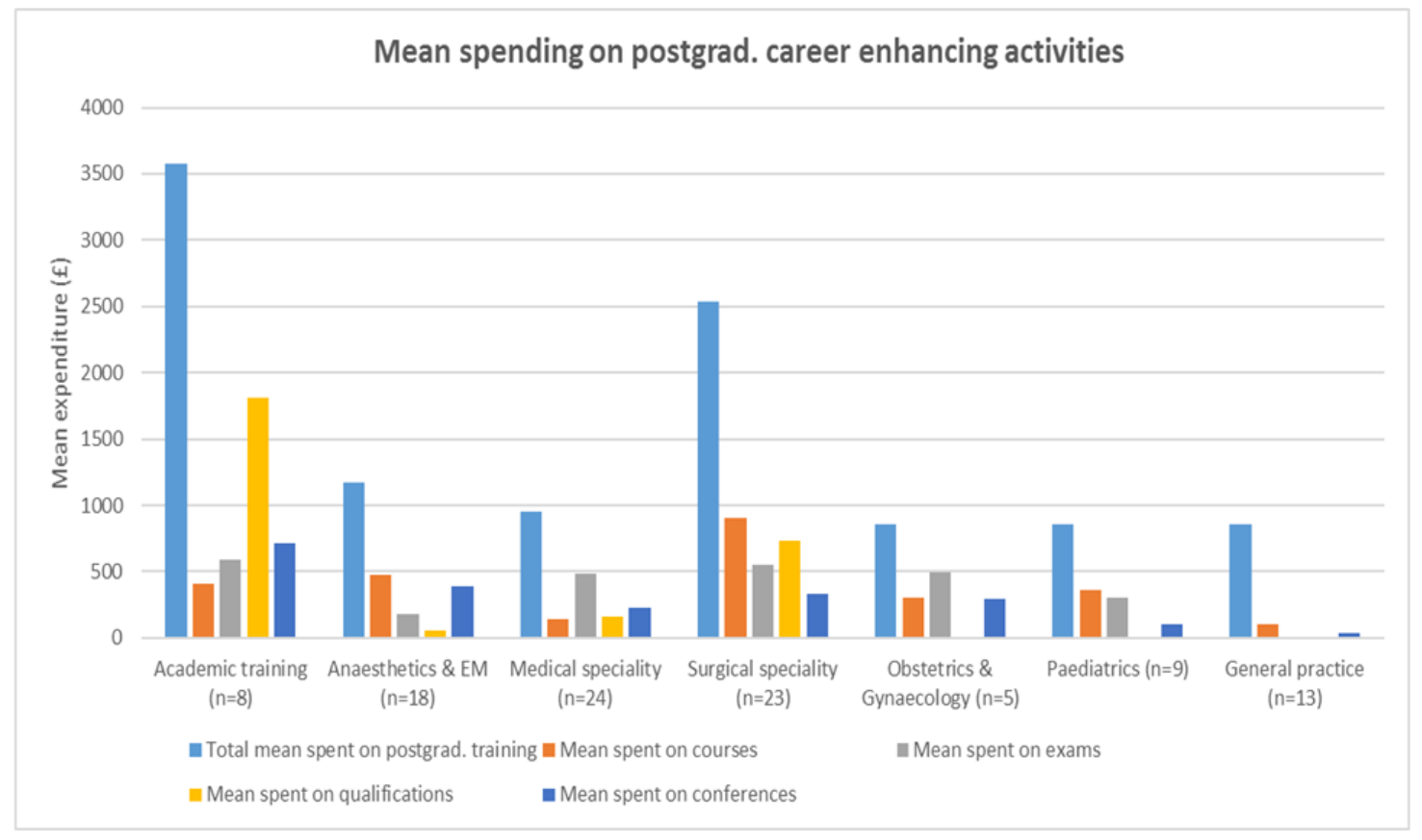

Fig. 1. Proportions of foundation doctors undertaking career enhancing activities across speciality application cohorts 
Table 2. Average spending on career enhancing activities, as a total and stratified by intended specialty

\begin{tabular}{|c|c|c|c|c|c|c|c|c|c|c|}
\hline \multirow[t]{2}{*}{ Intended specialty } & \multicolumn{2}{|c|}{ Total } & \multicolumn{2}{|c|}{ Training courses } & \multicolumn{2}{|c|}{ Postgraduate exams } & \multicolumn{2}{|c|}{$\begin{array}{l}\text { Postgraduate } \\
\text { qualifications }\end{array}$} & \multicolumn{2}{|c|}{ Attendance at conferences } \\
\hline & n (\%) & Mean spent (SD) & $\mathrm{n}(\%)$ & Mean spent (SD) & n (\%) & Mean spent (SD) & n (\%) & Mean spent (SD) & $\mathrm{n}(\%)$ & Mean spent (SD) \\
\hline Academic training & $8(8.0)$ & $3572(6650)$ & $4(50.0)$ & $406(425)$ & $8(100)$ & $594(371)$ & $1(12.5)$ & $1813(5127)$ & 7 (87.5) & $716(965)$ \\
\hline Anaesthetics \& EM* & $18(18.0)$ & $1171(843)$ & $11(61.1)$ & $476(474)$ & $4(22.2)$ & $183(402)$ & $0(0.0)$ & $60(232)$ & $12(66.7)$ & $390(353)$ \\
\hline Medical specialty & $24(24.0)$ & $948(782)$ & 8 (33.3) & $138(273)$ & $16(66.7)$ & $482(315)$ & $3(12.5)$ & $159(451)$ & $16(66.7)$ & $232(306)$ \\
\hline Surgical specialty & $23(23.0)$ & $2535(1804)$ & $20(87.0)$ & 903 (482) & $19(82.6)$ & $548(309)$ & $5(21.7)$ & $731(1688)$ & $15(65.2)$ & $328(406)$ \\
\hline Obstetrics \& Gynaecology & $5(5.0)$ & $859(137)$ & $3(60.0)$ & $300(388)$ & $3(60 \%)$ & $490(306)$ & $0(0.0)$ & $0(0)$ & $4(80.0)$ & $291(413)$ \\
\hline Paediatrics & $9(9.0)$ & 769 (454) & 7 (77.8) & 358 (303) & $5(55.6)$ & 306 (345) & $0(0.0)$ & $0(0)$ & $4(44.4)$ & 105 (263) \\
\hline General practice & $13(13.0)$ & $151(229)$ & $3(23.1)$ & $103(178)$ & $0(0.0)$ & $0(0)$ & $0(0.0)$ & $0(0)$ & $1(7.7)$ & $35(91)$ \\
\hline Total & $100(100)$ & $1460(2350)$ & $56(56.0)$ & $427(475)$ & $55(55.0)$ & $380(366)$ & $9(9.0)$ & 381 (1753) & $59(59.0)$ & $291(444)$ \\
\hline
\end{tabular}

${ }^{*}$ Anaesthetics \& EM includes applicants for both Acute Care Common Stem Anaesthetics or Emergency Medicine, and Core Anaesthetics. Abbreviations: EM, Emergency Medicine; SD, Standard Deviation 


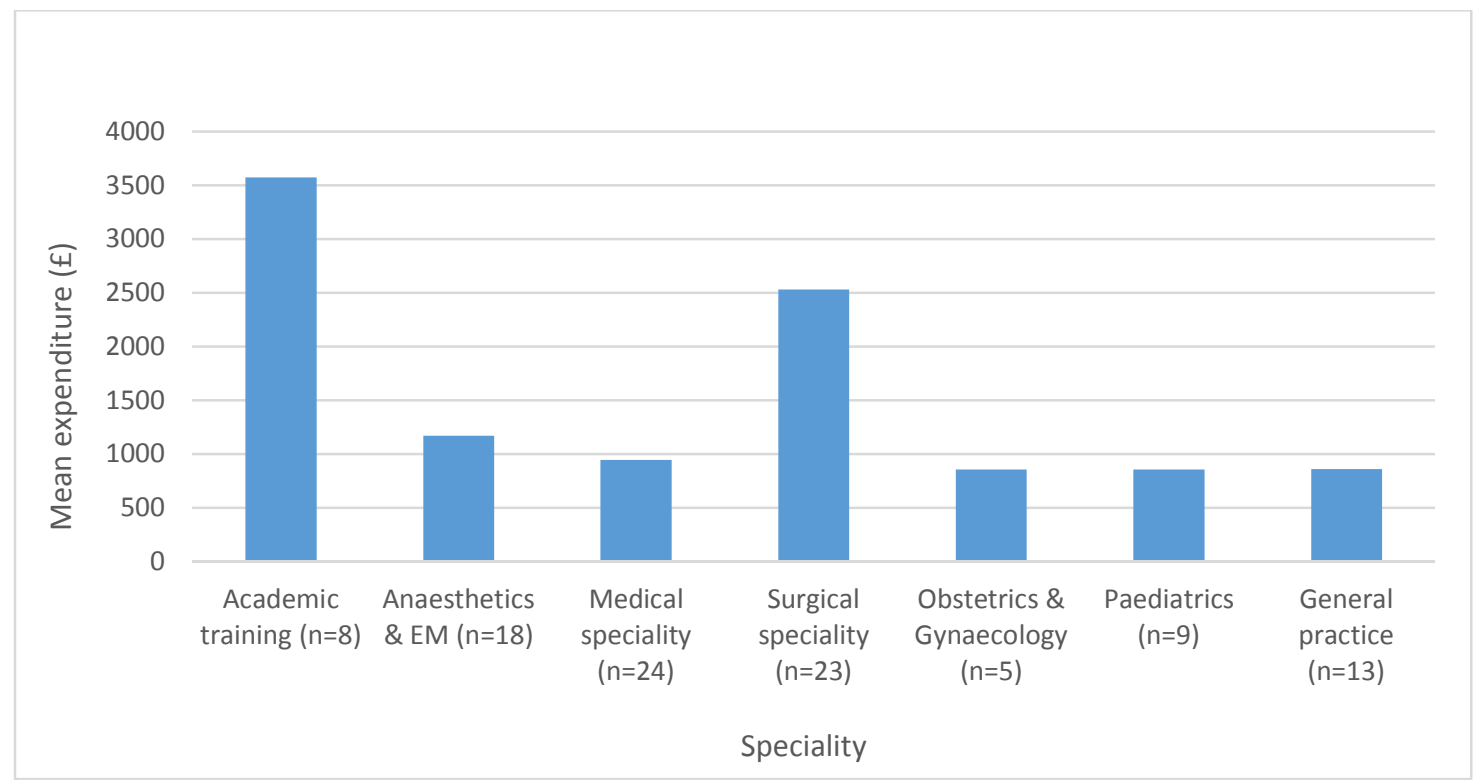

Fig. 2. Comparison of mean overall spending on career enhancing activities between foundation doctor speciality application cohorts

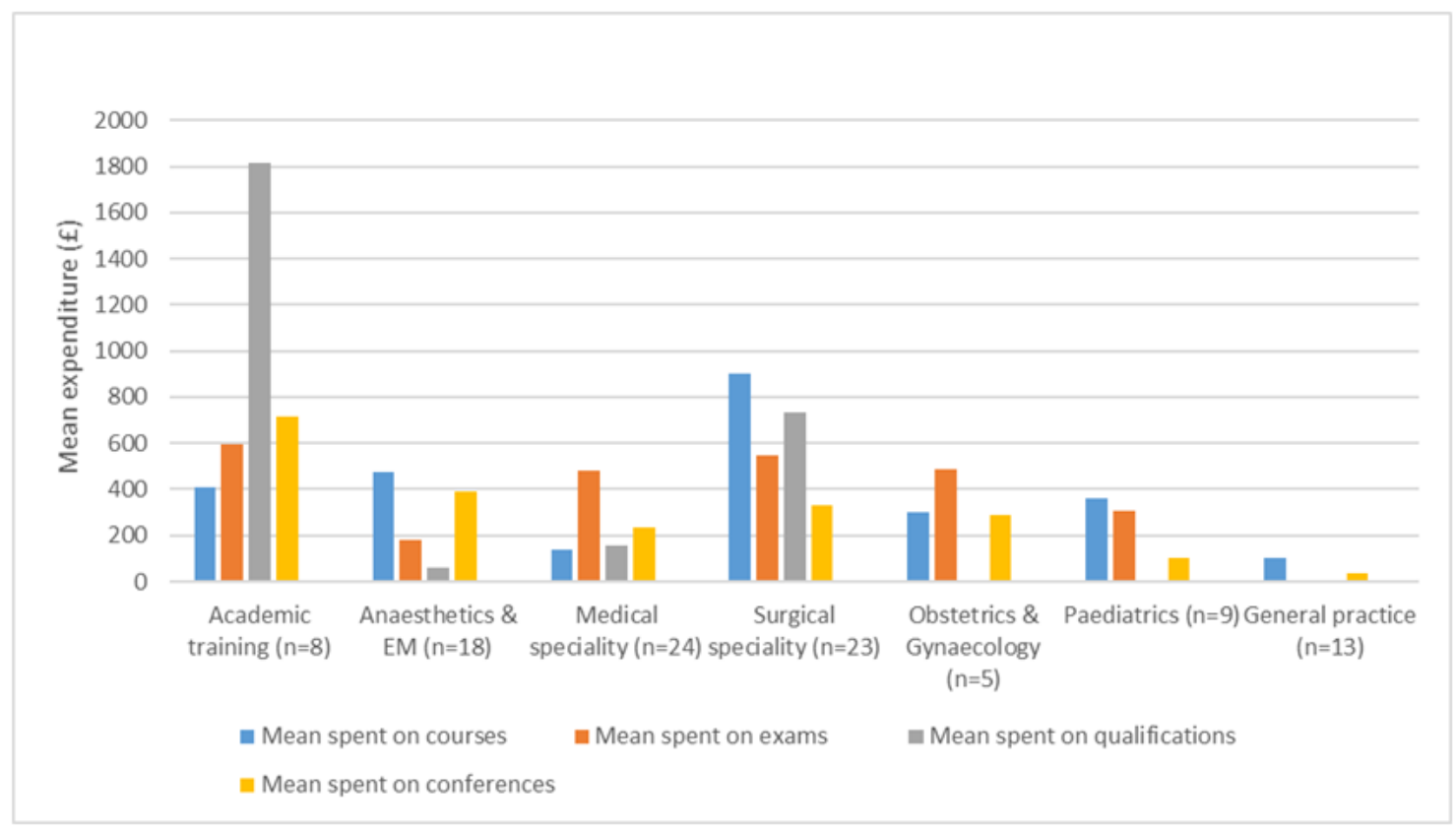

Fig. 3. Comparison of mean spending by foundation doctors per career enhancing activity across speciality application cohorts

\section{DISCUSSION}

This small study suggests that junior doctors in the UK are spending substantial but variable sums on career enhancing activities prior to applying for specialty training. This variation appears to relate to intended specialty, with those applying for more competitive areas such as clinical academia and surgical specialties [8] investing the greatest amount. Surgical and academic applicants in this study spent approximately double that of their colleagues 
applying for anaesthetics and medicine, and ten times more than applicants to general practice. However, these findings may be limited by response bias. A larger prospective study should be conducted to further investigate the variability in costs incurred by foundation trainees, and determine the means by which junior doctors are funding these activities.

In the current economic climate, the rising costs of clinical training are stark. Current UK medical graduates begin clinical work burdened by student debts of over $£ 57,000[2,4]$, and it is thought that the costs of medical postgraduate career-enhancing activities outweigh those of postgraduates in other fields such as law [2]. In the UK, Local Education and Training Boards (LETBs) are tasked with the distribution and utilisation of standardised national funding to provide education and training at a local level for healthcare professionals [9,10]. However, the quantity of monetary support provided at an individual level by this system is often relatively small $[11,12]$. This forces many junior doctors to spend significant amounts of their personal income to fund career-enhancing activities $[1,9,11]$.

This study suggests that applicants to clinical specialty training invest significantly variable amounts on career enhancing activities. Many trainees in this study were exceeding their allocated study budgets of $\sim £ 300-600$ per year [11]. The variable costs of early postgraduate career-enhancing activities could ostensibly play a significant role when junior doctors are deciding which specialty to apply for, potentially even superseding factors such as personal interest and enjoyment of the specialty [1]. This raises the question of whether it is appropriate to place such high weighting upon these activities during recruitment for early specialty training.

\section{CONCLUSION}

If the significant magnitude and variability in spending by foundation doctors identified in this work are corroborated by a larger study, Local Education and Training Boards could need to consider supporting this with compensatory modulation of Foundation Programme study budgets.

\section{CONSENT}

All authors declare that all survey participants gave informed consent for publication of this paper and accompanying figures.

\section{ETHICAL APPROVAL}

This work was granted ethical approval by the University of Bristol Research Ethics Committee.

\section{COMPETING INTERESTS}

Authors have declared that no competing interests exist.

\section{REFERENCES}

1. Jaques $H$. Junior doctors spend $£ 17114$ on postgraduate training. BMJ Careers; 2011.

(Accessed 14 ${ }^{\text {th }}$ June 2016)

Available:http://careers.bmj.com/careers/a dvice/view-article.html?id=20004902

2. Harrison E, Shaloub J. The cost of surgical training. Position statement by the Association of Surgeons in Training; 2007.

3. General Medical Council. Intercollegiate Surgical Curriculum. London: GMC; 2013.

4. British Medical Association. How much does it cost to train a doctor in the United Kingdom? Personal Social Services Research Unit, University of Kent; 2013. (Accessed 10 ${ }^{\text {th }}$ June 2016)

Available:https://webcache.googleusercont ent.com/search?q=cache:FMShmiQsSocJ: https://www.bma.org.uk//media/Files/Word\%2520files/News\%2520 views \%2520analysis/pressbriefing cost of training doctors.docx $+\& \mathrm{~cd}=2 \& \mathrm{hl}=\mathrm{en} \& \mathrm{ct}=$ clnk\&gl=uk

5. Mohammad A, Branicki F, Abu-Zidan FM. Educational and clinical impact of Advanced Trauma Life Support (ATLS) courses: A systematic review. World J Surg. 2014;38(2):322-29.

6. McLeod PJ, Brawer J, Steinert Y, Chalk C, McLeod A. A pilot study designed to acquaint medical educators with basic pedagogic principles. Med Teach. 2008; 30(1):92-93.

7. Foster K, Laurent R. How we make good doctors into good teachers: A short course to support busy clinicians to improve their teaching skills. Med Teach. 2013;35(1): 4-7.

8. Kennedy, C, Howes, J. Specialty training applications for 2015: Competition ratios and changes to the process. BMJ Careers; 2015.

(Accessed 13 ${ }^{\text {th }}$ December 2015) 
Available:http://careers.bmi.com/careers/a dvice/Specialty training applications for 2015\%3A competition ratios and change $\mathrm{s}$ to the process

9. British Medical Association. Postgraduate medical education and training - a new tariff system. BMA; 2014.

(Accessed 14 ${ }^{\text {th }}$ June 2016)

Available:https://www.bma.org.uk/advice/c areer/applying-for-training/education-andtraining-tariff

10. Health Education England. Hospitals, primary and community care. Health Education England; 2015.

(Accessed 14 $4^{\text {th }}$ June 2016)

Available:https://hee.nhs.uk/ourwork/hospitals-primary-community-care
11. Taylor J. Study leave guidelines for junior doctors. Royal Cornwall Hospitals NHS Trust; 2016.

(Accessed 4th June 2016)

Available:http://www.rcht.nhs.uk/Document sLibrary/RoyalCornwallHospitalsTrust/Web sites/Internet/OurServices/AZServices/P/P ostgraduateCentre/StudyLeave/StudyLeav eGuidelinesForJuniorDoctors.pdf

12. Government services and information. Education \& training tariffs; 2015. (Accessed 14 ${ }^{\text {th }}$ June 2016)

Available:https://www.gov.uk/government/ uploads/system/uploads/attachment data/f ile/390006/2015-16 Tariff guidance DRAFT - web version.pdf

(c) 2016 Bullock et al.; This is an Open Access article distributed under the terms of the Creative Commons Attribution License (http://creativecommons.org/licenses/by/4.0), which permits unrestricted use, distribution, and reproduction in any medium, provided the original work is properly cited.

Peer-review history:

The peer review history for this paper can be accessed here: http://sciencedomain.org/review-history/15942 